Original Research Paper

\title{
Infrared Thermography and Metabolic Changes in Castrated Piglets due to the Effects of Age and the Number of Incisions in the Testicles
}

\author{
${ }^{1}$ Efraín Pérez-Pedraza, ${ }^{2}$ Daniel Mota-Rojas, ${ }^{3}$ Miguel González-Lozano, \\ ${ }^{4}$ Isabel Guerrero-Legarreta, ${ }^{5}$ Julio Martínez-Burnes, ${ }^{6}$ Patricia Mora-Medina, \\ ${ }^{7}$ Rosy Cruz-Monterrosa and ${ }^{2}$ Ramiro Ramírez-Necoechea \\ ${ }^{I}$ Ph.D. Program in Biological and Health Sciences \\ [Programa de Doctorado en Ciencias Biológicas y de la Salud], \\ Universidad Autónoma Metropolitana, Mexico city. Mexico \\ ${ }^{2}$ Neurophysiology, behavior and assessment of welfare in domestic animals, DPAA. \\ Universidad Autónoma Metropolitana (UAM), Campus Xochimilco, Mexico City. Mexico \\ ${ }^{3}$ CEIEPP, FMVZ. Universidad Nacional Autónoma de México, Mexico City, Mexico \\ ${ }^{4}$ Department of Biotechnology, Universidad Autónoma Metropolitana, Campus Iztapalapa. México \\ ${ }^{5}$ Graduate Studies and Research, Veterinary Medicine Faculty, \\ Universidad Autónoma de Tamaulipas, Ciudad Victoria, Mexico \\ ${ }^{6}$ Department of Livestock Sciences, Universidad Nacional Autónoma de México, Mexico \\ ${ }^{7}$ Department of Food Science. Uiversidad Autónoma Metropolitana, Campus Lerma, Mexico
}

Article history

Received: 14-06-2018

Revised: $27-08-2018$

Accepted: 27-09-2018

Corresponding Author: Daniel Mota-Rojas,

Neurophysiology, behavior and assessment of welfare in

domestic animals. Universidad Autónoma Metropolitana,

Xochimilco. Calzada del Hueso 1100, Col. Villa Quietud, Del. Coyoacán, CP:04960, Mexico Tel/Fax: +525.55.54837535 Email: dmota100@yahoo.com.mx , dmota@correo.xoc.uam.mx

\begin{abstract}
The objective of the study was to evaluate infrared temperature and metabolic responses in different-aged piglets castrated surgically with one or two incisions. The piglets were divided into groups according to age (5- and 13-day old) and the number of incisions: simulated castration; castration with one incision (C1I5 and C1I13); and castration via two incisions (C2I5 and C2I13). Temperature evaluations were performed with an infrared thermal thermography camera in the eyes, the thorax and the scrotal area, at $24 \mathrm{~h}$ before castration (RV), immediately after castration (PC), 24 and $48 \mathrm{~h}$ post-surgery. The study also evaluated plasma glucose and lactate concentrations. The thorax presented lower infrared temperature in the groups C1I13 and C2I13 than those in C1I5 and C2I5 $(p<0.05)$. Regardless of age and type of castration, plasma lactate values increased PC $(\mathrm{P}=0.0001)$. The piglets castrated at 5 days of age were less susceptible to presenting temperature changes regardless of the number of incisions, while the animals castrated at 13 days with two incisions showed lower temperatures and imbalances in plasma glucose and lactate concentrations. Castration in piglets of 13 days causes a decrease in temperature in the lacrimal caruncle immediately after performing surgery. The physiological responses caused by castration are less marked in 5-day-old piglets.
\end{abstract}

Keywords: Castration, Piglets, Infrared Thermography, Metabolic Changes

\section{Introduction}

In most countries, pigs reared in pork-producing operations are castrated to obtain several wellrecognized benefits: (a) preventing unwanted breeding; (b) behavioral modifications that reduce fighting in mature pigs and make handling easier; and, (c) reducing the risk of boar taint in meat (Rault et al., 2011; Kluivers-Poodt et al., 2013; O'Connor et al., 2014).
While surgical castration is still the most common method used in the pork industry (Godyn et al., 2013), there is strong evidence that this surgery propitiates various stressful events that are likely to cause pain. These events include scrotal incisions, extraction of the testes and severing the spermatic cords (Bonastre et al., 2016). The stimulation of nociceptors in the scrotal skin activates neurons of various orders which transmit information from the periphery to the brain that can be interpreted as
Science

Publications
C 2018 Efraín Pérez-Pedraza, Daniel Mota-Rojas, Miguel González-Lozano, Isabel Guerrero-Legarreta, Julio MartínezBurnes, Patricia Mora-Medina, Rosy Cruz-Monterrosa and Ramiro Ramírez-Necoechea. This open access article is distributed under a Creative Commons Attribution (CC-BY) 3.0 license. 
pain and distress, regardless of the age at which the animals are castrated (McGlone and Hellman, 1988; Sutherland et al., 2010; Mota-Rojas et al., 2016). The most common procedure used by producers involves castrating piglets at 3-5 or 10-14 days of age (Nord et al., 2016). It is well-known that after a painful or stressful short-term handling event, catecholamine and glucocorticoid concentrations increase, stimulating the mobilization of muscular glycogen and the resulting hepatic metabolism that triggers increases in plasma lactate and glucose concentrations (Prunier et al., 2005; Lonardi et al., 2015); increases in metabolic activity that can generate higher core body temperatures (Carroll et al., 2006; Marchant-Forde et al., 2009; Weschenfelder et al., 2013). Infrared Thermography (IRT) is currently being used to detect the effects of painful, stressful and emotionallyupsetting stimuli on temperature changes in several species (Stubsjøen et al., 2009) that are believed to reflect internal body temperature (Kastberger and Stachl, 2003).

There are many reports in the literature of veterinary medicine that describe the benefits of local intratesticular, scrotal sac and spermatic cord anesthesia for controlling the pain and stress associated with the effects of castration in many species (Haga and Ranheim, 2005; Suriano et al., 2014; Nickell et al., 2015). They do not make recommendations as to how many scrotal incisions should be made, but the most common technique uses two incisions rather than one (Fredriksen et al., 2009). When two incisions are made, they are normally performed longitudinally on each testicle (Marsalek et al., 2015), while the single-incision method requires a transverse cut across both testicles and into the scrotum and tunica vaginalis (Kluivers-Poodt et al., 2013). Considering this background, the objective of the present study was to evaluate infrared temperature changes and metabolic responses in different-aged piglets castrated surgically with one or two incisions.

\section{Material and Methods}

\section{Geographical Location of the Experimental Site}

This study was conducted at a commercial pig farm in Amecameca located in the foothills of the Sierra Nevada, within the province of the volcanic axis and in the basin of the Moctezuma-Pánuco river. Geographic coordinates are longitude $\left(98^{\circ} 37^{\prime} 34^{\prime \prime}\right.$ y $98^{\circ} 49^{\prime} 10^{\prime \prime}$; latitude $19^{\circ} 3^{\prime} 12^{\prime \prime}$ y $\left.19^{\circ} 11^{\prime} 2^{\prime \prime}\right)$.

\section{Ethical Note}

All animals were handled humanely throughout the study. All procedures related to the use and care of the animals strictly followed the Mexican regulation norm, NOM-062-ZOO-1999 of Mexico's Department of Agriculture, Ranching, Rural Development, Fishing and Alimentation for animal-based experimentation (NOM, 1999).
This study was conducted at a commercial pig farm located in central Mexico, after obtaining approval from the Doctoral Commission of Biological Sciences of the Universidad Autonoma Metropolitana IztapalapaXochimilco in Mexico City in accordance with The Code of Ethics of the World Medical Association (Declaration of Helsinki). All procedures were conducted in accordance with the guidelines for the ethical use of animals in applied ethological studies, described elsewhere (Sherwin et al., 2003).

\section{Animals}

Data were collected from 72, 5- and 13-day-old male piglets (Yorkshire $\mathrm{x}$ Landrace) that weighed $1.68 \pm 0.40$ and $5.46 \pm 1.01 \mathrm{~kg}$, respectively. Piglets were obtained from twelve different litters delivered by third-parity sows. Piglets with abnormalities in the position of the testicles (unilateral or bilateral cryptorchidism, scrotal hernias, etc.) or signs of systemic disease were excluded. Following the regular handling practices at the host farm, on day 3 post-farrowing all piglets received a subcutaneous injection of $1 \mathrm{~mL}(100 \mathrm{mg})$ of $\mathrm{Fe}^{3+}$ in the form of iron dextran, then they were returned to the farrowing pen. The piglets were not subjected to tooth or tail resection before the experiment. The sows and their litters were held in 1.9-2.5 $\mathrm{m}^{2}$ cages and housed in individual farrowing crates made of tubing. Dimensions were $2.07 \mathrm{~m}$ long $\times 0.60 \mathrm{~m}$ wide $\times 101 \mathrm{~m}$ high, with a total space of $2 \mathrm{~m}$ wide by $2.5 \mathrm{~m}$ long. Each cage was equipped with a $50-\mathrm{cm}$ stainless steel feeder and a nipple drinker. An electric radiant lamp was used to heat the creep area in each crate. Each room held 12 far rowing crates, arranged in two rows of six crates separated by an aisle. The crates had fully-slatted floors made of wire mesh, covered with a plastic carpet. Ventilation and temperature were controlled automatically by fans and air heating $\left(27^{\circ} \mathrm{C}\right.$ and $60 \%$ relative humidity in the maternity room). Sows and piglets had ad libitum access to water in separate nipple drinkers. From day one of post-partum life, all piglets were weighed and identified individually by marking a number on their back. Different colors were used to distinguish the experimental groups. All these procedures were conducted by the same person.

Each one of the six study groups consisted of 12 piglets divided according to age and the number of incisions made during surgical castration, as follows: simulated castration (SC5 and SC13): a control group in which the 5- and 13-day old piglets, respectively, were removed from their pens and held in a head-down position by the legs for $120 \mathrm{~s}$; castration with one horizontal incision in both testicles in 5- and 13-day old piglets (C1I5 and $\mathrm{C} 1 \mathrm{I} 13$, respectively); and castration with two vertical scrotal incisions in 5- and 13-day old piglets (C2I5 and C2I13). 


\section{Surgical Procedure}

Before performing surgical castration, the scrotal area was superficially cleaned with chlorhexidine surgical scrub and isopropyl alcohol. Lidocaine at $10 \mathrm{mg} / \mathrm{ml}$ (Pisacaina 2\%, Pisa ${ }^{\circledR}$ Laboratorios, S.A. de C.V., Mexico) was used as the local anesthetic, with $0.5 \mathrm{ml}$ being injected into each testicle Hansson et al. (2011), with the expectation that it would spread from there into the spermatic cord. Those piglets were then returned to the crate with the other ones awaiting castration. Lidocaine was administered at least $15 \mathrm{~min}$ before castration in accordance with the methodology employed by Kluivers-Poodt et al. (2012).

Surgery for the piglets in groups C2I5 and C2I13 was performed with a scalpel to make two incisions in the scrotum, extract the testicles and sever the spermatic cords (Bonastre et al., 2016). For groups C1I5 and C1I13, castration was carried out by making one incision in the scrotum to expose the testicles. The spermatic cord was scarified with a scalpel and the testicles removed (Sturlini Barticciotto et al., 2016).

All surgical procedures were performed by experienced surgeons on the same day with the piglets restrained in the supine position by an assistant. The skin over the scrotum was tautened with one hand to help expose the testicles and incision site. Depending on the treatment group, castration was performed by making one or two incisions $(2-3 \mathrm{~cm})$ on the skin of the scrotum with a scalpel to expose the testicles. Next, the vaginal tunic and spermatic cords were cut and the testicles removed. Immediately after each castration, a healing agent was applied to the wound (Negasunt Powder 20 $\mathrm{Gm}^{\circledR}$ : Coumaphos: $3 \%$, Propoxur: $2 \%$, Prontalbin: $5 \%$ ). It is important to mention that no other post-operative treatment was applied.

\section{Infrared Thermal Camera}

Evaluation of the piglets' body temperature was performed with a portable infrared thermal camera (ThermaCam E45; FLIR Systems, Boston, MA, USA). Before beginning the study, the camera was calibrated for the temperature and relative humidity of the room where measurements were to be taken. The emissivity value used was 0.98 , as recommended by Soerensen and Pedersen (2015).

To avoid the confounding effect of ambient conditions on ocular temperature variation, a data logger; registering ambient temperature and relative humidity was attached to the camera while images were captured.

To optimize the accuracy of the thermographic image and to reduce sources of artifacts, before every testing session the same image of a Lambert Surface (An ideal, perfectly diffusing surface for which the intensity of reflected radiation is independent of direction) was taken to define the radiance emission and to nullify the effect of surface reflections on tested animals. All the electric radiant lamp and the ventilation system were turned off during the castration of the pigs and each time the infrared thermal camera was used. The sows were kept at an average room temperature of $26^{\circ} \mathrm{C} \pm 2$ with a relative humidity of $60 \%$. Lighting was set at 39.8 candelas.

While the piglets were restrained by the assistant and after drawing the blood samples, a second assistant -who was blind to the treatments- took three photographs of each region, as follows: the piglets' faces, to allow evaluation of both eyes (the area of the medial posterior palpebral border of the lower eyelid and the caruncula lacrimalis), the right flank and the scrotal area (Fig. 1). Three images of each body region were taken each time. The infrared thermographic images were captured at a distance of $50 \mathrm{~cm}$ from the piglets at the following intervals: $24 \mathrm{~h}$ prior to castration (Reference values, $\mathrm{RV}$ ), immediately after castration (PC) and at 24 and 48 h post-surgery. A total of 900 images were recorded as JPEG files using ThermaCam Researcher Basic image analysis software (FLIR Systems) to obtain minimum, average and maximum temperatures of the skin areas sampled. One clear infrared image (precise location and perfect focus) was chosen for each animal.

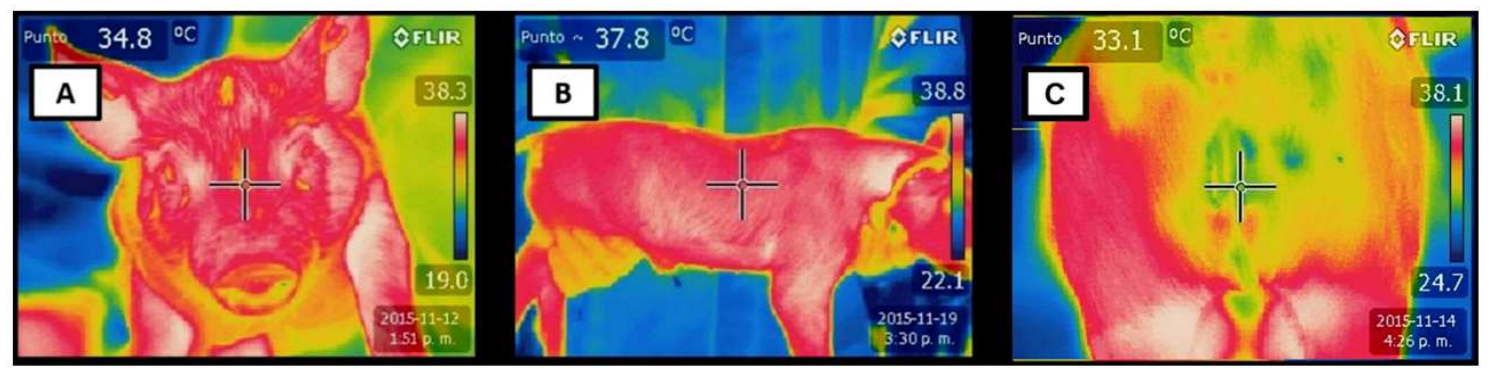

Fig. 1: Infrared thermographic images of surgically-castrated piglets. A = frontal infrared thermographic image showing measurement of the surface temperature of the eyes (small areas around the posterior border of the eyelid and the caruncula lacrimalis), $\mathrm{B}=$ infrared thermographic image showing the right side of the piglet to obtain the surface temperature of the thorax, $\mathrm{C}=$ infrared thermographic image of the scrotal wound made to perform surgical castration 


\section{Blood Samples}

Blood samples were collected immediately after the simulated or surgical castration from the cava cranialis vein using 3-ml syringes at four sampling time points: $24 \mathrm{~h}$ before castration (RV), immediately after surgery $(0 \mathrm{~h})$ and at 24 and $48 \mathrm{~h}$ post-castration. All samples were obtained in less than $20 \mathrm{~s}$ under physical restraint by placing the piglets in the same position as for castration. All personnel involved in sampling were experienced and had received training previously. Once obtained, $150 \mu \mathrm{L}$ of the samples from both age groups and type of castration were placed in a plasma gas and electrolyte parameter analyzer (GEM Premier, Instrumentation Laboratory Co., Lexington, USA and Instrumentation Laboratory SpA, Milano, Italy). Trained personnel processed all samples immediately to determine plasma glucose $(\mathrm{mg} / \mathrm{dL})$ and lactate levels $(\mathrm{mg} / \mathrm{dL})$.

\section{Statistical Analysis}

Normality assays were performed (PROC UNIVARIATE, SAS 9.0) for all variables examined, the two methods of castration considered and the two age groups to demonstrate the following: that errors had normal distributions and the existence of a null mean with a typical deviation $(\alpha)$. To test for the effect of age and castration method on temperature, a repeated measures ANOVA was performed (SAS 9.0). The researchers who carried out the evaluation and collected the study outcomes were not aware of the treatments and did not participate in selecting the animals or data analysis. Likewise, the researcher responsible for analyzing the data was unaware of the treatments. A two-tailed $p<0 \bullet 05$ was considered significant in every test.

\section{Results}

\section{Infrared Thermography of the Caruncula Lacrimalis in the Castrated Piglets}

Table 1 shows the infrared temperature values obtained for the caruncula lacrimalis of the piglets due to the effects of age and type of castration at the different sampling time points. Significant differences were observed among the age groups and types of castration, but only at $24 \mathrm{~h}$ post-castration in all groups.

Table 1: Temperature assessment $\left({ }^{\circ} \mathrm{C}\right.$ ) of the eyes (small areas around the posterior border of the eyelid and the caruncula lacrimalis) in castrated piglets by scrotal surgery with one or two incisions at 5 and 13 days of age

\begin{tabular}{|c|c|c|c|c|c|c|c|}
\hline \multirow[b]{3}{*}{ TIME } & \multicolumn{3}{|l|}{ Piglets 5d } & \multicolumn{3}{|l|}{ Piglets $13 \mathrm{~d}$} & \multirow[b]{3}{*}{ P-Value } \\
\hline & SC5 & C1I5 & $\mathrm{C} 2 \mathrm{I} 5$ & $\mathrm{SC} 13$ & $\mathrm{C} 1 \mathrm{I} 13$ & $\mathrm{C} 2 \mathrm{I} 13$ & \\
\hline & Mean \pm SEM & Mean \pm SEM & Mean \pm SEM & Mean \pm SEM & Mean \pm SEM & Mean \pm SEM & \\
\hline$\overline{\mathrm{RV}}$ & $35.35 \pm 0.42^{\mathrm{a} 1}$ & $35.72 \pm 0.26^{\mathrm{a} I}$ & $35.97 \pm 0.28^{\mathrm{aI}}$ & $36.30 \pm 0.37^{\mathrm{a} 1}$ & $36.40 \pm 0.25^{\mathrm{a} 1}$ & $35.95 \pm 0.24^{\mathrm{a} 1}$ & 0.25 \\
\hline $\mathrm{PC}$ & $35.35 \pm 0.58^{\mathrm{a} 1}$ & $35.33 \pm 0.38^{\mathrm{a} 1}$ & $35.50 \pm 0.52^{\mathrm{a} 1}$ & $34.72 \pm 0.44^{\mathrm{a} 2}$ & $34.54 \pm .33^{\mathrm{a} 2}$ & $34.31 \pm .33^{\mathrm{a} 2}$ & 0.22 \\
\hline $24 \mathrm{~h}$ & $36.00 \pm .56^{\mathrm{ab} 1}$ & $35.50 \pm 0.35^{\mathrm{a} 1}$ & $35.07 \pm 0.39^{\mathrm{a} 1}$ & $35.46 \pm 0.50^{\mathrm{ab} 12}$ & $34.33 \pm 0.34^{\mathrm{b} 2}$ & $33.98 \pm 0.32^{\mathrm{b} 2}$ & 0.0069 \\
\hline $48 \mathrm{~h}$ & $35.20 \pm 0.86^{\mathrm{a} 1}$ & $35.84 \pm 0.54^{\mathrm{a} 1}$ & $33.20 \pm 1.22^{\mathrm{a} 1}$ & $35.80 \pm 0.61^{\mathrm{a} 12}$ & $35.08 \pm 0.35^{\mathrm{a}, 12}$ & $35.34 \pm 0.35^{\mathrm{a} 12}$ & 0.48 \\
\hline P-Value & 0.51 & 0.62 & 0.09 & 0.003 & 0.0002 & 0.0029 & \\
\hline
\end{tabular}

SC5, simulated castration 5-day old piglets; C1I5, castration with one horizontal incision in both testicles in 5-day old piglets; C2I5, castration with two vertical scrotal incisions 5-day old piglets; SC13, simulated castration 13-day old piglets; C1I13, castration with one horizontal incision in both testicles in 13-day old piglets; C2I13, castration with two vertical scrotal incisions 13-day old piglets. SEM, standard error of the mean, RV, reference values (24 hours prior to castration); PC, post castration (immediately); $24 \mathrm{~h}, 24$ hours before castration; $48 \mathrm{~h}, 48$ hours post-surgery.

a, b, c Different letters in the same row indicate statistically significant differences among groups at the same time. ${ }^{1,2}$ Different numbers in the same column indicate statistically significant differences among times in the same group, Tukey $(\mathrm{p}<0.05)$.

Table 2: Temperature assessment $\left({ }^{\circ} \mathrm{C}\right)$ of the thorax surface in piglets castrated by scrotal surgery with one or two incisions at 5 and 13 days of age

\begin{tabular}{|c|c|c|c|c|c|c|c|}
\hline \multirow[b]{3}{*}{ TIME } & \multicolumn{3}{|l|}{ Piglets 5d } & \multicolumn{3}{|l|}{ Piglets $13 \mathrm{~d}$} & \multirow[b]{3}{*}{ P-Value } \\
\hline & SC5 & C1I5 & $\mathrm{C} 2 \mathrm{I} 5$ & $\mathrm{SC} 13$ & C1I13 & $\mathrm{C} 2 \mathrm{I} 13$ & \\
\hline & Mean \pm SEM & Mean \pm SEM & Mean \pm SEM & Mean \pm SEM & Mean \pm SEM & Mean \pm SEM & \\
\hline$\overline{\mathrm{RV}}$ & $37.52 \pm 0.45^{\mathrm{a} 1}$ & $37.51 \pm 0.28^{\mathrm{a}}$ & $37.41 \pm 0.30^{\mathrm{a} 1}$ & $36.58 \pm 040^{\mathrm{a}}$ & $36.78 \pm 0.27^{\mathrm{a} I}$ & $37.13 \pm 0.26^{\mathrm{aI}}$ & 0.26 \\
\hline PC & $37.00 \pm 0.67^{\mathrm{a} 1}$ & $36.65 \pm 0.47^{\mathrm{a} 1}$ & $37.46 \pm 0.54^{\mathrm{a} 1}$ & $35.90 \pm 0.42^{\mathrm{a} 1}$ & $35.69 \pm 0.30^{\mathrm{a} 1}$ & $35.74 \pm 0.27^{\mathrm{a} 2}$ & 0.05 \\
\hline $24 \mathrm{~h}$ & $37.40 \pm 0.59^{\mathrm{ab} 1}$ & $37.63 \pm 0.37^{\mathrm{a} 1}$ & $37.68 \pm 0.42^{\mathrm{a} 1}$ & $35.90 \pm 0.53^{\mathrm{ab} 1}$ & $35.74 \pm 0.34^{\mathrm{b} 1}$ & $35.74 \pm 0.34^{\mathrm{b} 2}$ & 0.0003 \\
\hline $48 \mathrm{~h}$ & $37.30 \pm 0.61^{\mathrm{a} 1}$ & $36.98 \pm 0.38^{\mathrm{a} 1}$ & $36.20 \pm 0.86^{\mathrm{a} 1}$ & $35.45 \pm 0.43^{\mathrm{a} 1}$ & $36.51 \pm 0.27^{\mathrm{a} 1}$ & $36.48 \pm 0.24^{\mathrm{a} 1}$ & 0.13 \\
\hline P-Value & 0.93 & 0.08 & 0.32 & 0.33 & 0.11 & 0.0048 & \\
\hline
\end{tabular}

SC5, simulated castration 5-day old piglets; C1I5, castration with one horizontal incision in both testicles in 5-day old piglets; C2I5, castration with two vertical scrotal incisions 5-day old piglets; SC13, simulated castration 13-day old piglets; C1I13, castration with one horizontal incision in both testicles in 13-day old piglets; C2I13, castration with two vertical scrotal incisions 13-day old piglets. SEM, standard error of the mean, RV, reference values (24 hours prior to castration); PC, post castration (immediately); $24 \mathrm{~h}, 24$ hours before castration; $48 \mathrm{~h}, 48$ hours post-surgery

${ }_{\mathrm{a}, \mathrm{b}, \mathrm{c}}$ Different letters in the same row indicate statistically significant differences among groups at the same time. ${ }^{1,2}$ Different numbers in the same column indicate statistically significant differences among times in the same group, Tukey $(\mathrm{p}<0.05)$. 
At that time, the piglets in group $\mathrm{C} 1 \mathrm{I} 13$ presented a temperature that was $1.17^{\circ} \mathrm{C}$ below that of the piglets in group C1I5. Also, the piglets in group C2I13 presented an infrared temperature that was $1.09^{\circ} \mathrm{C}$ lower than that of the piglets in group C2I5 $(p<0.05)$. The C2I13 piglets had lower infrared temperatures immediately after castration and at $24 \mathrm{~h}$ post-surgery, compared to the RV; however, infrared temperatures returned to RV at $48 \mathrm{~h}$ post-castration.

\section{Infrared Thermography of the Thorax Surface in Castrated Piglets}

The infrared temperature values from the surface of the thorax are shown in Table 2 at $24 \mathrm{~h}$ post-castration. The $\mathrm{C} 1 \mathrm{I} 13$ and $\mathrm{C} 2 \mathrm{I} 13$ piglets presented an average infrared temperature that was $1.64^{\circ} \mathrm{C}$ lower than that of the piglets in group $\mathrm{SC} 13$ and $1.12^{\circ} \mathrm{C}$ lower than the piglets in groups C1I5 and C2I5. Also, the SC13 and C2I13 piglets had reduced infrared temperatures immediately after castration and at $24 \mathrm{~h}$ post-surgery, compared to the RV. However, temperatures in all groups returned to $\mathrm{RV}$ at $48 \mathrm{~h}$ post-castration.

\section{Infrared Thermography of the Scrotal Surface in Castrated Piglets}

Table 3 shows the infrared temperature values for the scrotal region of the piglets due to the effects of age and type of castration at the different sampling time points. Our results may suggest that immediately after castration, the piglets in $\mathrm{C} 1 \mathrm{I} 13$ and $\mathrm{C} 2 \mathrm{I} 13$ presented infrared temperatures that were $1.95^{\circ} \mathrm{C}$ and $2.44^{\circ} \mathrm{C}$ lower, respectively, than the temperature values determined for SC13.

At $24 \mathrm{~h}$ post-castration, the $\mathrm{C} 1 \mathrm{I} 13$ group presented an infrared temperature that was $2.32^{\circ} \mathrm{C}$ lower than that of group C1I5. Also, group $\mathrm{C} 2 \mathrm{I} 13$ had an infrared temperature $2.14^{\circ} \mathrm{C}$ lower than group C2I5 $(\mathrm{p}<0.05)$. In contrast, the measurements taken at $48 \mathrm{~h}$ post-surgery showed an infrared temperature that was $1.480 \mathrm{C}$ lower in group C1I13 than in C1I5 ( $\mathrm{p}=0.029)$.

In relation to the infrared temperatures evaluated within each age group at the different sampling time points, observations showed that values decreased immediately after castration by one or two incisions in the C1I5 and C2I5 piglets, but no alterations at 24 and 48 $\mathrm{h}$ post-castration, compared to the RV $(\mathrm{p}<0.05)$. The C2I13 piglets, in contrast, showed a marked decrease in their temperature values immediately after castration that were maintained up to $24 \mathrm{~h}(\mathrm{p}<0.05)$.

\section{Glucose}

Table 4 presents the plasma glucose values of the piglets in both age groups castrated by one or two incisions. The study found significant differences between the baseline values of the 5- and 13-day-old piglets, with the latter registering higher plasma glucose values $(p<0.05)$. Other observations showed that immediately after surgery, the C2I13 piglets presented higher plasma glucose values than the 5-day-old piglets castrated by one or two incisions $(\mathrm{p}<0.05)$.

\section{Lactate}

Figure 2 shows the plasma lactate values for the piglets in both age groups castrated by one or two incisions. These results indicate that immediately after surgery, C1I13 animals had higher plasma lactate levels than the C1I5 piglets castrated by the same technique and the piglets in the simulation group. In other results, at $24 \mathrm{~h}$, the study found that the piglets C2I5 had higher plasma lactate values than the 13-day-old animals in the simulated castration group and the piglets C1I13 $(\mathrm{p}<0.05)$. Regarding evaluation time, results show that, regardless of age and type of castration, plasma lactate values increased immediately after surgery and in the piglets with simulated castration $(\mathrm{p}=0.0001)$.

Table 3: Temperature assessment $\left({ }^{\circ} \mathrm{C}\right)$ of the scrotal surface in castrated piglets by scrotal surgery with one or two incisions at 5 and 13 days of age

\begin{tabular}{|c|c|c|c|c|c|c|c|}
\hline \multirow[b]{3}{*}{ TIME } & \multicolumn{3}{|l|}{ Piglets $5 d$} & \multicolumn{3}{|l|}{ Piglets $13 \mathrm{~d}$} & \multirow[b]{3}{*}{ P-Value } \\
\hline & SC5 & $\mathrm{C} 1 \mathrm{I5}$ & $\mathrm{C} 2 \mathrm{I} 5$ & $\mathrm{SC} 13$ & $\mathrm{C} 1 \mathrm{I} 13$ & $\mathrm{C} 2 \mathrm{I} 13$ & \\
\hline & Mean \pm SEM & Mean \pm SEM & Mean \pm SEM & Mean \pm SEM & Mean \pm SEM & Mean \pm SEM & \\
\hline$\overline{\mathrm{RV}}$ & $37.75 \pm 0.62^{\mathrm{a} 1}$ & $37.33 \pm 0.44^{\mathrm{a} 1}$ & $36.64 \pm 0.41^{\mathrm{a} 1}$ & $36.94 \pm 0.56^{\mathrm{a} 1}$ & $36.07 \pm 0.37^{\mathrm{a} l}$ & $36.58 \pm 0.36^{\mathrm{a} 1}$ & 0.18 \\
\hline $\mathrm{PC}$ & $36.55 \pm 0.65^{\mathrm{a} 1}$ & $35.38 \pm 0.34^{\mathrm{ab} 2}$ & $35.33 \pm 0.53^{\mathrm{abc} 2}$ & $36.08 \pm 0.41^{\mathrm{a} 1}$ & $34.13 \pm 0.32^{\mathrm{bc} 1}$ & $33.64 \pm 0.27^{\mathrm{c} 3}$ & 0.0001 \\
\hline $24 \mathrm{~h}$ & $36.47 \pm 0.67^{\mathrm{ab} 1}$ & $36.97 \pm 0.42^{\mathrm{a} 1}$ & $36.80 \pm 0.47^{\mathrm{a} 1}$ & $35.25 \pm 0.67^{\mathrm{ab} 1}$ & $34.65 \pm 0.42^{\mathrm{b} 1}$ & $34.66 \pm 0.40^{\mathrm{b} 23}$ & 0.0005 \\
\hline $48 \mathrm{~h}$ & $37.65 \pm 0.59^{\mathrm{a} 1}$ & $36.960 .37^{\mathrm{a} 1}$ & $35.90 \pm 0.84^{\mathrm{ab} 12}$ & $35.86 \pm 0.48^{\mathrm{ab} 1}$ & $35.48 \pm 0.28^{\mathrm{b} 1}$ & $35.30 \pm .24^{\mathrm{b} 12}$ & 0.029 \\
\hline P-Value & 0.2 & 0.0005 & 0.02 & 0.07 & 0.05 & 0.0001 & \\
\hline
\end{tabular}

SC5, simulated castration 5-day old piglets; C1I5, castration with one horizontal incision in both testicles in 5-day old piglets; C2I5, castration with two vertical scrotal incisions 5-day old piglets; SC13, simulated castration 13-day old piglets; C1I13, castration with one horizontal incision in both testicles in 13-day old piglets; C2I13, castration with two vertical scrotal incisions 13-day old piglets. SEM, standard error of the mean, RV, reference values (24 hours prior to castration); PC, post castration (immediately); $24 \mathrm{~h}, 24$ hours before castration; $48 \mathrm{~h}, 48$ hours post-surgery.

a, b, c Different letters in the same row indicate statistically significant differences among groups at the same time. ${ }^{1,2}$ Different numbers in the same column indicate statistically significant differences among times in the same group, Tukey $(\mathrm{p}<0.05)$ 
Table 4: Plasma glucose concentration $(\mathrm{mg} / \mathrm{dL})$ in piglets castrated by scrotal surgery with one or two incisions at 5 and 13 days of age during a period of $48 \mathrm{~h}$ post-surgery

\begin{tabular}{|c|c|c|c|c|c|c|c|}
\hline \multirow[b]{3}{*}{ TIME } & \multicolumn{3}{|l|}{ Piglets 5d } & \multicolumn{4}{|l|}{ Piglets $13 \mathrm{~d}$} \\
\hline & SC5 & C1I5 & $\mathrm{C} 2 \mathrm{I} 5$ & SC13 & C1I13 & C2I13 & \\
\hline & Mean \pm SEM & Mean \pm SEM & Mean \pm SEM & Mean \pm SEM & Mean \pm SEM & Mean \pm SEM & P-Value \\
\hline RV & $89.00 \pm 5.38^{\mathrm{d} 1}$ & $94.81 \pm 3.63^{\mathrm{cd} 1}$ & $97.27 \pm 3.63 b^{\text {cd } 1}$ & $117.80 \pm 5.38^{\mathrm{a} 1}$ & $111.27 \pm 3.63^{\mathrm{ab} 1}$ & $109.63 \pm 3.63^{\mathrm{abcl}}$ & 0.0002 \\
\hline $\mathrm{PC}$ & $102.20 \pm 8.20^{\mathrm{ab} 1}$ & $99.90 \pm 5.53^{\mathrm{b} 1}$ & $94.90 \pm 5.80^{\mathrm{b} 1}$ & $100 \pm 60 \pm 8.20^{\mathrm{ab} 1}$ & $118.63 \pm 5.53^{\mathrm{ab} 1}$ & $124.45 \pm 5.53^{\mathrm{a} 1}$ & 0.003 \\
\hline $24 \mathrm{~h}$ & $104.20 \pm 6.72^{\mathrm{a} 1}$ & $101.12 \pm 5.31^{\mathrm{a} 1}$ & $99.55 \pm 5.01^{\mathrm{a} 1}$ & $107.00 \pm 6.72^{\mathrm{a} 1}$ & $105.72 \pm 4.53^{\mathrm{a} 1}$ & $106.18 \pm 4.53^{\mathrm{a} 1}$ & 0.89 \\
\hline $48 \mathrm{~h}$ & $109.75 \pm 7.21^{\mathrm{a} 1}$ & $98.63 \pm 4.35^{\mathrm{a} 1}$ & $107.33 \pm 4.80^{\mathrm{a} 1}$ & $120.75 \pm 7.21^{\mathrm{a} 1}$ & $109.72 \pm 4.35^{\mathrm{a} 1}$ & $102.50 \pm 4.56^{\mathrm{a} 1}$ & 0.14 \\
\hline P-Value & 0.33 & 0.65 & 0.17 & 0.29 & 0.27 & 0.06 & \\
\hline
\end{tabular}

SC5, simulated castration 5-day old piglets; C1I5, castration with one horizontal incision in both testicles in 5-day old piglets; C2I5, castration with two vertical scrotal incisions 5-day old piglets; SC13, simulated castration 13-day old piglets; C1I13, castration with one horizontal incision in both testicles in 13-day old piglets; C2I13, castration with two vertical scrotal incisions 13-day old piglets. SEM, standard error of the mean, RV, reference values ( $24 \mathrm{~h}$ prior to castration); PC, post castration (immediately); $24 \mathrm{~h}, 24 \mathrm{~h}$ before castration; $48 \mathrm{~h}, 48$ hours post-surgery.

$a, b, c$ Different letters in the same row indicate statistically significant differences among groups at the same time. ${ }^{1,2}$ Different numbers in the same column indicate statistically significant differences among times in the same group, Tukey $(p<0.05)$

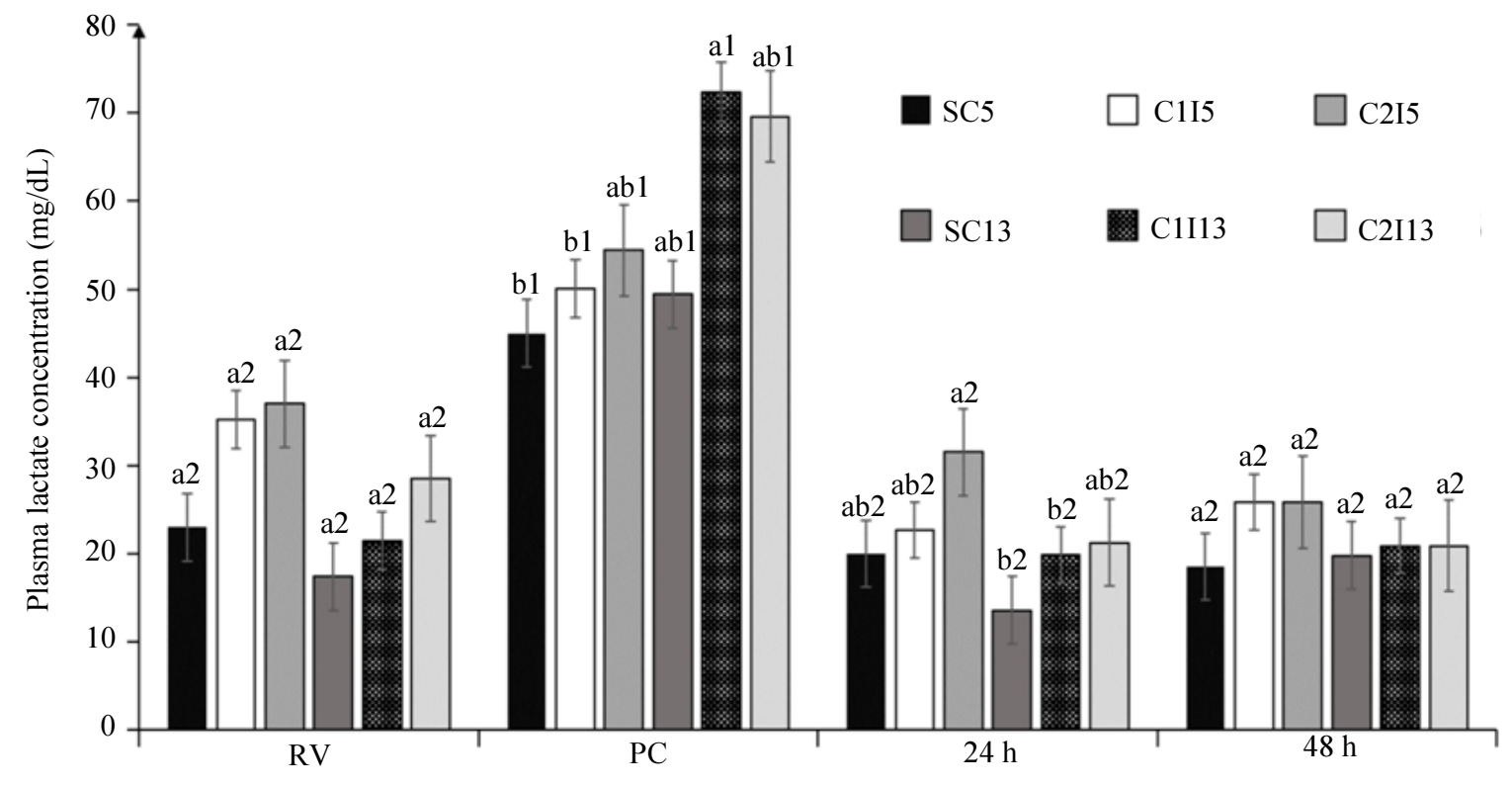

Time (h)

Fig. 2: Plasma lactate concentration $(\mathrm{mg} / \mathrm{dL})$ in piglets castrated by scrotal surgery with one or two incisions at 5 and 13 days of age during a period of $48 \mathrm{~h}$ post-surgery. SC5 $=$ simulated castration 5 -day old piglets, C1I5 = castration with one horizontal incision in both testicles in 5-day old piglets, C2I5 = castration with two vertical scrotal incisions 5-day old piglets, SC13= simulated castration 13-day old piglets, C1I13 = castration with one horizontal incision in both testicles in 13-day old piglets, C2I13 = castration with two vertical scrotal incisions 13-day old piglets

${ }^{\mathrm{a}, \mathrm{b}, \mathrm{c}}$ Different letters indicate statistically significant differences among groups at the same time. ${ }^{1,2}$ Different numbers indicate statistically significant differences among times in the same group, Tukey $(\mathrm{p}<0.05)$

\section{Discussion}

The results of this study include the observation that the age at which castration was performed added to the number of incisions made in the scrotum generated changes in the infrared thermographic temperatures in different areas of the body, as well as modifications of plasma glucose and lactate levels. These alterations can be interpreted as indirect indicators of stress.
Our results indicate that castrating piglets at 13 days of age provoked changes in infrared temperatures when compared to the piglets that had surgery at 5 days of age. In this regard, Guatteo et al. (2012) reported that the age of animals plays a role in pain responses to castration, as these are less pronounced in younger subjects than older ones. Likewise, Janczak et al. (2012) observed that 14day-old piglets had a higher mechanical nociceptive pain 
threshold, which may be related to their higher age and weight compared to younger, 7-day-old, piglets and could produce a lower capacity for responding to pain in younger piglets. McGlone and Hellman (1988), meanwhile, compared castration in piglets at 2 vs. 7 weeks of age. They found that using local anesthesia eliminated pain-induced behaviors in the younger subjects, but appeared to be ineffective in the older ones (White et al., 1995; Von Borell et al., 2009). Findings of this nature may help explain the results of our study with respect to the alterations in infrared temperatures and energy metabolism that the younger piglets manifested, despite the application of local anesthesia. The results presented here in could be interpreted as suggesting that it is more advisable to perform castration under anesthesia when animals are younger. Also, Taylor et al. (2001) indicate that piglets experience no less pain when castrated at less than 1 week of age vs. 2 or 3 weeks.

In other findings, the responses to castration observed in our study include decreased temperatures in the eye, thorax and scrotal wound. In this regard, changes in skin temperature have been shown to be associated with both clinical and emotional responses in humans and other animal species, while rapid changes in blood flow can be associated with stress responses (Yarnell et al., 2013). When an animal becomes stressed, the HPA axis is activated and the generation of heat, due to increases in catecholamine and cortisol levels and blood flow responses, produces changes in temperature and heat loss (Schaefer et al., 2012; Mota-Rojas et al., 2011). Stressinduced hyperthermia occurs in numerous species, characterized by an increase in core body temperature but a decrease in surface temperature of 0.5 -to- $1.5^{\circ} \mathrm{C}$ within 10-15 min of the onset of "emotional stress" (Edgar et al., 2013; Mota-Rojas et al., 2011, 2012b; 2016). This coincides with the results of our study, where the surface temperature of the piglets decreased immediately after castration, regardless of the number of incisions made. In this respect, studies of castrated piglets by Lonardi et al. (2015) reported an increase in the temperature of the eye 20 minutes after surgery, or a simulation of this, which differs from the findings of our study, where the temperature reduction in the 13-day-old piglets continued up to $24 \mathrm{~h}$ post-surgery. It is important to note that decreases in eye temperature have also been reported in other species faced with different stressor stimuli; for example, eye temperatures in birds decreased with handling (Herborn et al., 2015) and it has been suggested that the drop in eye temperature seen in dehorned bovines following disbudding without local anesthetic may be caused by sympathetic vasoconstriction (Stewart et al., 2008). The decrease in eye temperature may also be due to the presence of a network of venous blood from the nasal cavity that is cooler and whose function is to lower the temperature of the blood that irrigates the brain. Hence, this blood may also decrease the temperature of the eye and the small areas around the posterior border of the eyelid and the caruncula lacrimalis (Loughmiller et al., 2001; Stewart et al., 2007). We should point out that in addition to the decrease in eye temperature, the 13-day-old piglets also had lower thorax temperatures. This phenomenon may be explained by the activation of SNS, which produces pupillary dilatation, higher blood pressure and heart rate, peripheral vasoconstriction and, consequently, a decrease in skin surface temperatures, while activation of the sympathetic branch induces an increase in core temperature (brain and upper organs), but decreases in the temperatures of more peripheral body areas, such as the nose, face and ears. This is caused by vasoconstriction, which controls the conduction of heat to the skin by the blood in the arterioles and arteriovenous anastomoses that supply it to the venous plexus of the skin (Guyton and Hall, 1996; McCafferty et al., 2011; Yarnell et al., 2013; Bonastre et al., 2016; Travain et al., 2016). Soerensen and Pedersen (2015) evaluated the surface temperature of piglets after removal of their incisors. They found that this practice causes increased levels of noradrenaline, whose vasoconstrictor effect can reduce blood flow to the skin and, as a result, decrease temperatures. Menzel et al. (2014) presented the hypothesis that reduced thorax temperatures could be caused by physiological ventilation of lung tissue with cool air. Thus, with regard to the temperature changes in the wound caused by castration, our study found an evident decrease in all groups that underwent surgery, but that this was more pronounced in the 13-day-old piglets. This result may be due to the fact that vasoconstriction in the skin in response to a stressful stimulus is a specific regional response (Herpin et al., 2004); that is, an initial acute response to stress that, presumably, acts to increase perfusion pressure and redirect blood flow to organs and the skeletal musculature, areas that have more urgent metabolic requirements. Vasoconstriction of the blood vessels that supply the skin also protects against excessive loss of blood in the event of damage to external tissue (Stewart et al., 2007). This mechanism for preventing excessive blood loss could explain the more marked temperature reduction in the $\mathrm{C} 2 \mathrm{I} 13$ piglets. It is important to note that the first response to wounds is hemostasis, which occurs within a matter of minutes to stop bleeding and seal off the wound through the action of three mechanisms: the aggregation of platelet clumps, vasoconstriction and the formation of a fibrin clot (Clark et al., 1996; Kimani, 2013). It is probable that when a reduction of blood flow to the wound occurs, white blood cells are trapped at the capillary level. This results in the plugging of capillary loops that produce areas of localized ischemia. Finally, in the inflammatory phase, platelets aggregate and form clots to minimize blood and fluid loss at the wound site (Paz and West, 2013). 
With regards to the increase in plasma glucose levels in the 13-day-old piglets immediately after castration, it is well-known that this index is considered an indirect indicator of stress in pigs, because in response to that condition glu $\neg$ cose levels rise due to catecho $\neg$ lamine and glucocorticoid secretion (Pollard et al., 2002; MotaRojas et al., 2011; 2012b). In addition, Von Borell et al. (2009) mention that castration induces physiological and behavioral reactions that are indicative of pain, while also generating stress and discomfort before and after surgery. These reactions are of great magnitude during surgery and in the initial hours following it. Other studies point out that increases in plasma glucose concentrations may occur due to the breakdown of glycogen from the liver, or the depletion of glycogen reserves from skeletal muscles (Tadich et al., 2005; Averós et al., 2008; Martínez-Rodríguez et al., 2015; Mota-Rojas et al., 2011; 2012b). These findings suggest that castration is more stressful for piglets when performed at higher ages. However, it is important to remember that assessing pain requires an integrated, multi-disciplinary approach that includes both behavioral and physiological approaches, because of the different ways in which individual animals respond to stressors (Gottardo et al., 2016).

Turning now to plasma lactate levels, all the castrated piglets -regardless of age- presented an increase in this metabolite immediately after castration. In this regard, several studies of adult (Becerril-Herrera et al., 2010; Mota-Rojas et al., 2012a) and neonate (MartínezRodríguez et al., 2011) pigs have demonstrated that increases in plasma lactate concentrations can result from exposure to different stressors. Lactate is a metabolite that causes muscular glycogenolysis due to a lack of glucose phosphatase 6, which is necessary for glycogen synthesis (Mota-Rojas et al., 2012b). The lactate that forms in the muscle is transported through the bloodstream to the liver, where it is transformed into glucose (Moberg, 2000; Pollard et al., 2002). Prunier et al. (2005) found higher concentrations of blood lactate in piglets following castration compared to non-castrated animals, since a significant proportion of the stress/discomfort that they experience results from handling procedures (Leidig et al., 2009). In light of this evidence, we can conclude that the physiological changes seen in the piglets in the present study could be associated with the pain generated by castration when this surgery is performed at a younger age, regardless of the number of incisions.

\section{Conclusion}

In conclusion, the castration of piglets at 13 days of age with one incision generates more metabolic imbalances associated with stress and pain, the lower infrared temperature values in the caruncula lacrimalis and thorax. Likewise, piglets castrated by two incisions at 5 and 13 days of age have adverse effects to a lesser degree. Although castrations by one incision in piglets of 5 days have less adverse effects, it is necessary to continue investigating other clinical indicators.

Therefore, our recommendation is that castration should be done in piglets during the first 5 days postpartum to prevent imbalances in their energy metabolism and changes in surface temperature.

\section{Acknowledgements}

Efraín Pérez Pedraza is enrolled in the Doctoral Program in Biological and Health Sciences at the Universidad Autónoma Metropolitana.

\section{Author's Contributions}

Daniel Mota-Rojas: Participated in the conception and project design.

Efraín Pérez Pedraza: Collected field samples, generated the data and statistically analysed the data.

Isabel Guerrero-Legarreta, Julio Martínez Burnes, Ramiro Ramírez-Necoechea, Miguel González-Lozano, Patricia Mora-Medina, Daniel MotaRojas, Efraín Pérez Pedraza and Rosy CruzMonterrosa: Interpreted the data and wrote the draft paper.

DMR, JMB, IGL, RRN and MGL: Provided substantial intellectual input and edited the manuscript.

DMR, IGL, RRN, MGL and PMM: Financed the project. All authors gave final approval for publication.

\section{Ethics}

This article is original and contains unpublished material. The corresponding author confirms that all of the other authors have read and approved the manuscript and there are no ethical issues involved.

\section{References}

Averós, X., S. Martin, M. Riu, J. Serratosa and L. Gosalvez, 2008. Stress response of extensively reared young bulls being transported to growingfinishing farms under Spanish summer commercial conditions. Livest. Sci., 119: 174-182.

DOI: 10.1016/j.livsci.2008.04.002

Becerril-Herrera, M., M. Alonso-Spilsbury, M.T. Ortega, I. Guerrero-Legarreta and R. Ramírez-Necoechea et al., 2010. Changes in blood constituents of swine transported for 8 or $16 \mathrm{~h}$ to an Abattoir. Meat Sci., 86: 945-948. DOI: 10.1016/j.meatsci.2010.07.021

Bonastre, C., O. Mitjana, M. Tejedor, M. Calavia and A. Yuste et al., 2016. Acute physiological responses to castration-related pain in piglets: The effect of two local anesthetics with or without meloxicam. Animal, 10: 1474-1481.

DOI: $10.1017 / \mathrm{S} 1751731116000586$ 
Carroll, J., E. Berg, T. Strauch, M. Roberts and H. Kattesh, 2006. Hormonal profiles, behavioral responses and short-term growth performance after castration of pigs at three, six, nine, or twelve days of age. J. Anim. Sci. 84: 1271-1278. DOI: $10.2527 / 2006.8451271 \mathrm{x}$

Clark, R., M.G Tonnesen, J. Gailit and D.A Cheresh, 1996. Transient functional expression of alphaVbeta 3 on vascular cells during wound repair. Am. J. Pathol., 148: 1407.

Edgar, J., C. Nicol, C. Pugh and E. Paul, 2013. Surface temperature changes in response to handling in domestic chickens. Physiol. Behav., 119: 195-200. DOI: 10.1016/j.physbeh.2013.06.020

Fredriksen, B., M.F.I. Furnols, K. Lundstrom, W. Migdal and A. Prunier et al., 2009. Practice on castration of piglets in Europe. Animal, 3: 1480-1487. DOI: $10.1017 / \mathrm{S} 1751731109004674$

Godyn, D., E. Herbut and J. Walczak, 2013. Infrared thermography as a method for evaluating the welfare of animals subjected to invasive proceduresA review. Ann. Anim. Sci., 13: 423-434. DOI: $10.2478 /$ aoas-2013-0027

Gottardo, F., A. Scollo, B. Contiero, A. Ravagnani and G. Tavella et al., 2016. Pain alleviation during castration of piglets: A comparative study of different farm options. J. Animal Sci., 94: 5077-5088. DOI: $10.2527 /$ jas.2016-0843

Guatteo, R., O. Levionnois, D. Fournier, D. Guemene and K. Latouche et al., 2012. Minimising pain in farm animals: The 3S approach-'Suppress, Substitute, Soothe'. Animal, 6: 1261-1274. DOI: $10.1017 / \mathrm{S} 1751731112000262$

Guyton, A. and J. Hall, 1996. Metabolism and Temperature Regulation: Textbook of Medical Physiology, 9th Edn., Philadelphia: WB Saunders Co, pp: 914-915.

Haga, H.A. and B. Ranheim, 2005. Castration of piglets: The analgesic effects of intratesticular and intrafunicular lidocaine injection. Vet. Anaesth. Anal., 32: 1-9. DOI: $10.1111 / \mathrm{j} .1467-2995.2004 .00225 . \mathrm{x}$

Hansson, M., N. Lundeheim, G. Nyman and G. Johansson, 2011. Effect of local anaesthesia and/or analgesia on pain responses induced by piglet castration. Acta Vet. Scand., 53: 34.

DOI: $10.1186 / 1751-0147-53-34$

Herborn, K.A., J.L Graves, P. Jerem, N.P. Evans and R. Nager et al., 2015. Skin temperature reveals the intensity of acute stress. Physiol. Behav., 152: 225-230. DOI: 10.1016/j.physbeh.2015.09.032

Herpin, P., A. Vincent and M. Damon, 2004. Effect of breed and body weight on thermoregulatory abilities of European (Pietrain $\times($ Landrace $\times$ Large White $)$ ) and Chinese (Meishan) piglets at birth. Livest. Prod. Sci., 88: 17-26.

DOI: $10.1016 /$ j.livprodsci.2003.11.006
Janczak, A.M., B. Ranheim, T.K. Fosse, S. Hild and J. Nordgreen et al., 2012. Factors affecting mechanical (nociceptive) thresholds in piglets. Vet. Anaesth. Anal., 39: 628-635.

DOI: $10.1111 /$ j.1467-2995.2012.00737.x

Kastberger, G. and R. Stachl, 2003: Infrared imaging technology and biological applications. Behav. Res. Meth. Ins., 35: 429-439.

Kimani, J.M., 2013. Comparative skin morphology and wound healing in Kenyan African mole rat (tachyoryctes ibeanus) and naked mole rat (heterocephalus glaber). $\mathrm{PhD}$ Thesis University of Nairobi.

Kluivers-Poodt, M., B. Houx, S. Robben, G. Koop and E. Lambooij et al., 2012. Effects of a local anaesthetic and NSAID in castration of piglets, on the acute pain responses, growth and mortality. Animal, 6: 1469-1475. DOI: $10.1017 / \mathrm{S} 1751731112000547$

Kluivers-Poodt, M., J.J. Zonderland, J. Verbraak, E. Lambooij and L.J. Hellebrekers, 2013. Pain behaviour after castration of piglets; effect of pain relief with lidocaine and/or meloxicam. Animal, 7: 1158-1162. DOI: $10.1017 / \mathrm{S} 1751731113000086$

Leidig, M.S., B. Hertrampf, K. Failing, A. Schumann and G. Reiner, 2009. Pain and discomfort in male piglets during surgical castration with and without local anaesthesia as determined by vocalisation and defence behaviour. App. Anim. Behav., Sci., 116: 174-178. DOI: 10.1016/j.applanim.2008.10.004

Lonardi, C., A. Scollo, S. Normando, M. Brscic and F. Gottardo, 2015. Can novel methods be useful for pain assessment of castrated piglets? Animal, 9: 871-877. DOI: 10.1017/S1751731114003176

Loughmiller, J.A., M.F. Spire, S.S. Dritz, B.W. Fenwick and M.H. Hosni et al., 2001. Relationship between mean body surface temperature measured by use of infrared thermography and ambient temperature in clinically normal pigs and pigs inoculated with Actinobacillus pleuropneumoniae. Am. J. Vet. Res., 62: 676-681. DOI: 10.2460/ajvr.2001.62.676

Marchant-Forde, J., D. Lay, K. McMunn H.W. Cheng and E. Pajor et al., 2009. Postnatal piglet husbandry practices and well-being: The effects of alternative techniques delivered separately. J. Anim. Sci., 87: 1479-1492. DOI: $10.2527 /$ jas.2008-1080

Marsalek, P., M. Svoboda, J. Bernardy and V. Vecerek, 2015. Concentrations of neopterin, biopterin and cortisol associated with surgical castration of piglets with lidocaine. Czech J. Anim. Sci., 60: 473-478. DOI: $10.17221 / 8555-C J A S$

Martínez-Rodríguez, R., D. Mota-Rojas, M.E. TrujilloOrtega, H. Orozco-Gregorio and R. HernándezGonzález et al., 2011. Physiological response to hypoxia in piglets of different birth weight. Ital. J. Anim. Sci., 10: e56. DOI: 10.4081/ijas.2011.e56 
Martínez-Rodríguez, R., P. Roldan-Santiago, H. OrozcoGregorio, M. Trujillo-Ortega and P. Mora-Medina et al., 2015. Physiological responses and blood gas exchange following long-distance transport of piglets weaned at different ages over unpaved or paved roads. Livest. Sci., 172: 69-78.

DOI: $10.1016 /$ j.livsci.2014.12.013

McCafferty, D., C. Gilbert, W. Paterson, P. Pomeroy and D. Thompson et al., 2011. Estimating metabolic heat loss in birds and mammals by combining infrared thermography with biophysical modelling. Comp. Biochim. Phys., 158: 337-345.

DOI: 10.1016/j.cbpa.2010.09.012

McGlone, J.J. and J. Hellman, 1988. Local and general anesthetic effects on behavior and performance of two-and seven-week-old castrated and uncastrated piglets. J. Anim. Sci., 66: 3049-3058.

DOI: $10.2527 /$ jas 1988.66123049x

Menzel, A., M. Beyerbach, C. Siewert, M. Gundlach and D. Hoeltig et al., 2014. Actinobacillus pleuropneumoniae challenge in swine: Diagnostic of lung alterations by infrared thermography. BMC Vet. Res., 10: 1. DOI: 10.1186/s12917-014-0199-2

Moberg, G., 2000. Biological response to stress: Implications for animal welfare: The biology of animal stress. Basic Principles and Implications for Animal Welfare, pp: 1-21.

Mota-Rojas, D., H. Orozco-Gregorio, D. VillanuevaGarcia, H. Bonilla-Jaime and X. Suarez-Bonilla et al., 2011. Foetal and neonatal energy metabolism in pigs and humans: A review. Vet. Med., 56: 215-225.

Mota-Rojas, D., M. Becerril-Herrera, P. RoldanSantiago, M. Alonso-Spilsbury and S. FloresPeinado et al., 2012a. Effects of long distance transportation and $\mathrm{CO}_{2}$ stunning on critical blood values in pigs. Meat Sci., 90: 893-898.

DOI: $10.1016 /$ j.meatsci.2011.11.027

Mota-Rojas, D., J. Martinez-Burnes, D. Villanueva-Garcia, P. Roldan-Santiago and M. Trujillo-Ortega et al., 2012b. Animal welfare in the newborn piglet: A review. Vet. Med., 57: 338-349.

Mota-Rojas, D., M.A. Ceballos, A. Orihuela, M.A. Corredor and E. Pérez et al., 2016. Chapter 11. Painful practices in farm animals. In: Bienestar Animal, Una Vision Global en Iberoamérica [Animal welfare, a global vision in Ibero-America], MotaRojas, D., A. Velarde, S.M. Huertas-Canén and M.N. Cajíao (Eds.), Elsevier, Barcelona, pp: 137-4.

Nickell, J., L.S. Barter and J.E. Dechant, 2015. Effects of Intratesticular and Incisional Local Anesthetic Administration for Castration of Alpacas Anesthetized with Intramuscular KetamineXylazine-Butorphanol. Vet. Surg., 44: 168-173. DOI: 10.1111/j.1532-950X.2014.12285.x
NOM, 1999. 062-ZOO-1999: Especificaciones Técnicas para la Producción, Cuidado y Uso de loa animales de Laboratorio. Diario Oficial de la Federación de los Estados Unidos Mexicanos, AFIA 6.

Nord, A., M. Lehmann, R. MacLeod, D.J. McCafferty and R.G. Nager et al., 2016. Evaluation of two methods for minimally invasive peripheral body temperature measurement in birds. J. Avian Biol., 47: 417-427. DOI: $10.1111 /$ jav.00845

O'Connor, A., R. Anthony, L. Bergamasco, J. Coetzee and S. Gould et al., 2014. Pain management in the neonatal piglet during routine management procedures. Part 2: Grading the quality of evidence and the strength of recommendations. Anim. Health. Res. Rev., 15: 39-62.

DOI: $10.1017 / \mathrm{S} 1466252314000073$

Paz, J.C. and M.P. West, 2013. Acute Care Handbook for Physical Therapists. 4th Edn., Elsevier Health Sciences, United Satates.

Pollard, J., R. Littlejohn, G. Asher, A. Pearse and J. Stevenson-Barry et al., 2002. A comparison of biochemical and meat quality variables in red deer (Cervus elaphus) following either slaughter at pasture or killing at a deer slaughter plant. Meat Sci., 60: 85-94. DOI: $10.1016 / \mathrm{S} 0309-1740(01) 00110-3$

Prunier, A., A. Mounier and M. Hay, 2005. Effects of castration, tooth resection, or tail docking on plasma metabolites and stress hormones in young pigs. J. Anim. Sci., 83: 216-222. DOI: $10.2527 / 2005.831216 \mathrm{x}$

Rault, J.L., D.C. Lay and J.N. Marchant-Forde, 2011. Castration induced pain in pigs and other livestock. App. Anim. Behav. Sci., 135: 214-225. DOI: 10.1016/j.applanim.2011.10.017

Schaefer, A., N. Cook, C. Bench, J. Chabot and J. Colyn et al., 2012. The non-invasive and automated detection of bovine respiratory disease onset in receiver calves using infrared thermography. Res. Vet. Sci., 93: 928-935.

DOI: 10.1016/j.rvsc.2011.09.021

Sherwin, C.M., S.B. Christiansen, I.J. Duncan, H.W Erhard and D.C. Lay et al., 2003. Guidelines for the ethical use of animals in applied ethology studies. App. Anim. Behav. Sci., 81: 291-305. DOI: 10.1016/S0168-1591(02)00288-5

Soerensen, D.D. and L.J. Pedersen, 2015. Infrared skin temperature measurements for monitoring health in pigs: A review. Acta Vet. Scand., 57: 5. DOI: 10.1186/s13028-015-0094-2

Stewart, M., J. Webster, G. Verkerk, A. Schaefer and J. Colyn et al., 2007. Non-invasive measurement of stress in dairy cows using infrared thermography. Physiol. Behav., 92: 520-525.

DOI: 10.1016/j.physbeh.2007.04.034 
Stewart, M., K. Stafford, S. Dowling, A. Schaefer and J. Webster, 2008. Eye temperature and heart rate variability of calves disbudded with or without local anaesthetic. Physiol. Behav., 93: 789-797.

DOI: 10.1016/j.physbeh.2007.11.044

Stubsjøen, S.M., A.S. Flø, R.O. Moe, A.M. Janczak and E. Skjerve et al., 2009. Exploring non-invasive methods to assess pain in sheep. Physiol. Behav., 98: 640-648. DOI: 10.1016/j.physbeh.2009.09.019

Sturlini Barticciotto, L., S.P. Loureiro Luna, S.E.F. Rodolfo de Sá Lorena and D.A., Garcia Telles Berto, 2016. Weight gain, behavioral and cortisol changes after orchiectomy with or without local anaesthesia in piglets. Semina: Ciências Agrárias. DOI: $10.5433 / 1679-0359.2016 v 37 n 3 p 1307$

Suriano, R., V. Varasano, D. Robbe, A. Carluccio and P. Straticò et al., 2014. Intraoperative analgesic effect of intrafunicular lidocaine injection during orchiectomy in isoflurane-anesthetized martina franca donkeys. J. Equine Vet. Sci., 34: 793-798. DOI: $10.1016 /$ j.jevs.2014.02.002

Sutherland, M., B. Davis, T. Brooks and J. McGlone, 2010. Physiology and behavior of pigs before and after castration: Effects of two topical anesthetics. Animal, 4: 2071-2079. DOI: $10.1017 / \mathrm{S} 1751731110001291$

Tadich, N., C. Gallo, H. Bustamante, M. Schwerter and G. Van Schaik, 2005. Effects of transport and lairage time on some blood constituents of Friesiancross steers in Chile. Livest. Prod. Sci., 93: 223-233. DOI: 10.1016/j.livprodsci.2004.10.004
Taylor, A.A., D.M. Weary, M. Lessard and L. Braithwaite, 2001. Behavioural responses of piglets to castration: The effect of piglet age. App. Anim. Behav. Sci., 73: 35-43. DOI: $10.1016 / \mathrm{S} 0168-1591(01) 00123-\mathrm{X}$

Travain, T., E.S. Colombo, L.C. Grandi, E. Heinzl and A. Pelosi et al., 2016. How good is this food? A study on dogs' emotional responses to a potentially pleasant event using infrared thermography. Physiol. Behav., 159: 80-87.

DOI: 10.1016/j.physbeh.2016.03.019

Von Borell, E., J. Baumgartner, M. Giersing, N. Jäggin and A. Prunier et al., 2009. Animal welfare implications of surgical castration and its alternatives in pigs. Animal, 3: 1488-1496. DOI: $10.1017 / \mathrm{S} 1751731109004728$

Weschenfelder, A.V., L. Saucier, X. Maldague, L.M. Rocha and A.L. Schaefer et al., 2013. Use of infrared ocular thermography to assess physiological conditions of pigs prior to slaughter and predict pork quality variation. Meat Sci., 95: 616-620. DOI: 10.1016/j.meatsci.2013.06.003

White, R., J. DeShazer, C. Tressler, G. Borcher and S. Davey et al., 1995. Vocalization and physiological response of pigs during castration with or without a local anesthetic. J. Animal Sci., 73: 381-386. DOI: $10.2527 / 1995.732381 \mathrm{x}$

Yarnell, K., C. Hall and E. Billett, 2013. An assessment of the aversive nature of an animal management procedure (clipping) using behavioral and physiological measures. Physiol. Behav., 118: 32-39. DOI: 10.1016/j.physbeh.2013.05.013 